\title{
Effects of Electrode Surface Topography on Aluminum Resistance Spot Welding
}

\author{
Electrode face topography is found to significantly influence \\ resistance heat generation and electrode cooling effects
}

BY L. DENG, Y.-B. LI, B. E. CARLSON, AND D. R. SIGLER

\begin{abstract}
Automotive lightweighting is one of the most important means to achieve the mandatory fuel efficiency requirements as established in the Corporate Average Fuel Economy Standards (CAFE), USA. To achieve this goal, lightweight materials such as aluminum alloys are utilized to fabricate vehicle bodies. However, the surface oxide found on aluminum alloy components poses significant challenges to traditional resistance spot welding (RSW) processes. This has driven many automotive manufacturers to apply self-piercing riveting as the preferred aluminum assembly joining method. To enable RSW as a common joining process for steel or aluminum body structures in a single body shop, General Motors (GM) previously developed electrodes with weld face designs that include sharp radii of curvature and surface topographies to mitigate the effects of oxide layers on aluminum alloys by reducing contact resistance. This paper explores, through microstructural analysis and mechanical property testing, the effect of electrode weld face topographies upon the resistance spot welding of 1.2-mm-thick 6022-T4 aluminum sheets welded to itself. For comparison, three types of electrode face designs were systematically studied: A textured electrode and a Multi-Ring Domed (MRD) electrode having two ring heights (e.g., Ring $\mathrm{Hl}$ and $\mathrm{H} 2$ ). The results indicate that the electrode face topography can significantly influence resistance heat generation and electrode cooling effects, as well as produce welds with unique morphology, microstructure, and mechanical properties.
\end{abstract}

\section{KEYWORDS}

- Resistance Spot Welding • Al Alloys • Mechanical Properties • Weldability - Electrode Surface Topography

\section{Introduction}

The application of lightweight materials such as aluminum in automotive body structures is a strategic approach to achieve the mandatory fuel efficiency requirements as established in the Corporate Average Fuel Economy Standards (CAFE), USA (Ref. 1). When used to replace steel, aluminum alloy components can achieve mass reductions of $30 \sim 40 \%$ (Ref. 2). For example, the Cadillac CT6 is $218 \mathrm{lb}$ lighter than an equivalent steel vehicle because of the advanced manufactur- ing methods combined with a mixed material structure that includes all aluminum exterior body panels (Ref. 3). Conventional steel bodies use resistance spot welding (RSW) for assembly of the body structure. The use of the same equipment to weld aluminum (Al) to Al joints would provide manufacturing flexibility and save significant floor space and cost. However, the surface oxide layers found on aluminum alloy components pose significant challenges to traditional RSW processes. This has driven many automotive manufacturers to apply self- piercing riveting (SPR) as the preferred aluminum-assembly joining method. SPR is an effective process to join aluminum alloys; however, it does add cost and mass to the process as well as introduces a third body that affects the electrochemical potential of the joint (Ref. 5).

Resistance spot welding is a complicated process coupling mechanical, metallurgical, thermal, and electrical phenomena (Ref. 5). It has been widely used to join steels in the automotive industry because of its inherently low cost, as well as high throughput, automation level, and adaptability (Ref. 6). However, RSW of aluminum alloys faces significant challenges because of its high thermal and electrical conductivity, high coefficient of thermal expansion, low melting temperature, and oxide layers that form on the metal surface. Because the thermal and electrical conductivity of aluminum alloys is approximately $3 \times$ that of steels, significantly higher currents have traditionally been applied though welding times onefourth to one-third of that used for steel RSW (Ref. 7). To avoid excessive heating at the electrode/sheet interface and possible external weld metal expulsion, significantly larger weld face diameters and radii of curvature have been used, which drives wide flange requirements while reducing process robustness. Furthermore, accurate control and synchronization of current and electrode force are required due to the narrow weld temperature range (Ref. 8).

Most important of all, the presence of oxide layers on the sheet surface induces a dynamic contact resistance at 

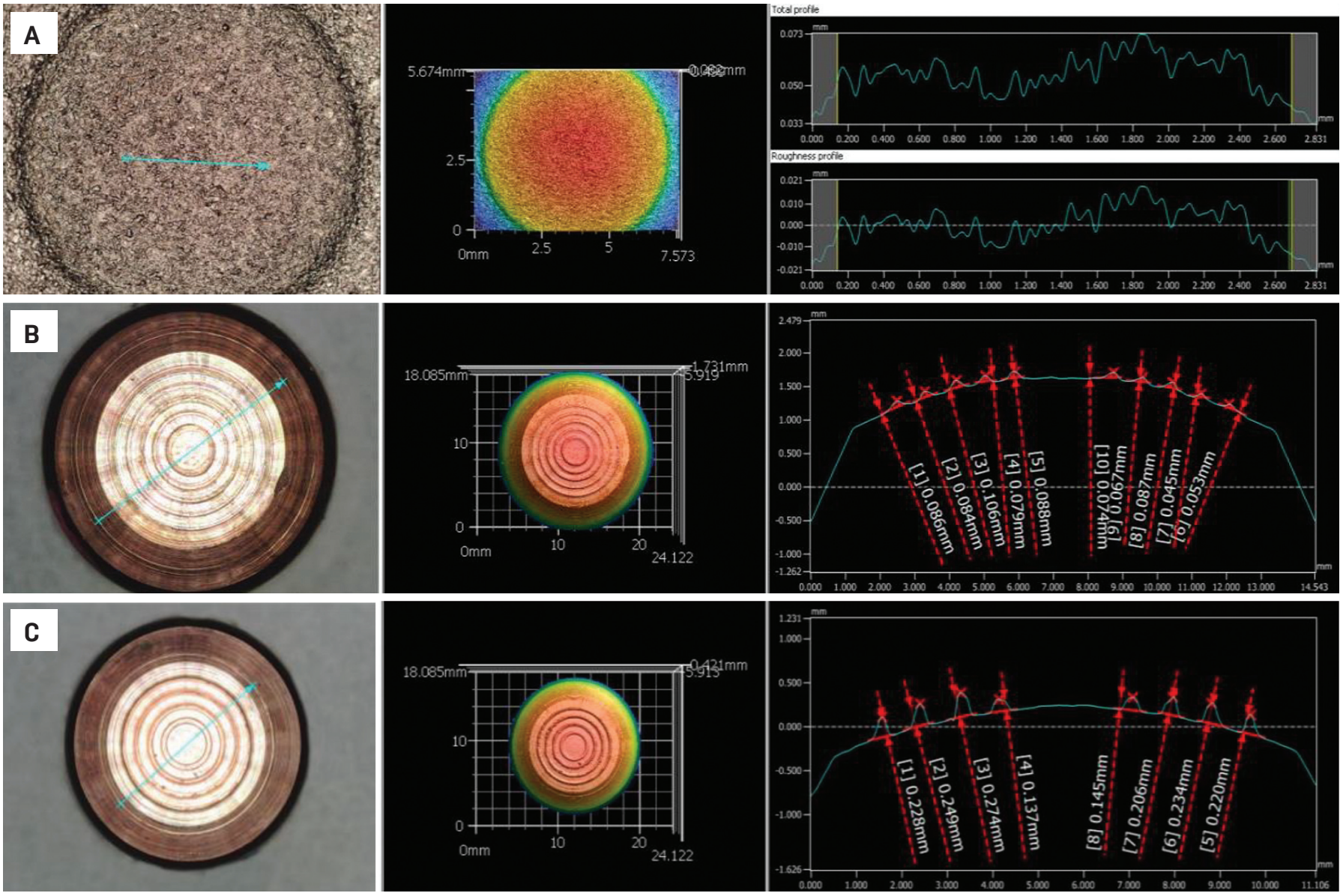

Fig. 1 - Electrode weld face profiles extracted from laser confocal 3D measurement: A - Textured; B - MRD Ring HI; C - MRD Ring H2.

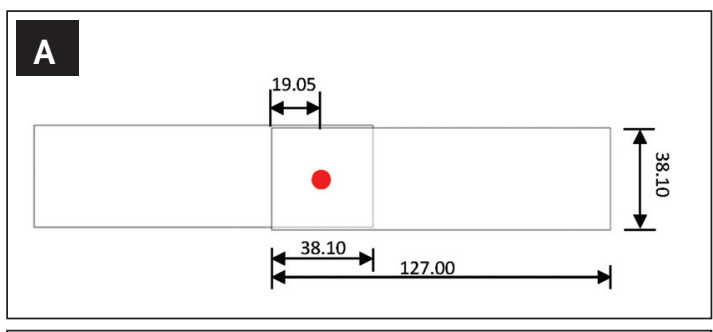

B

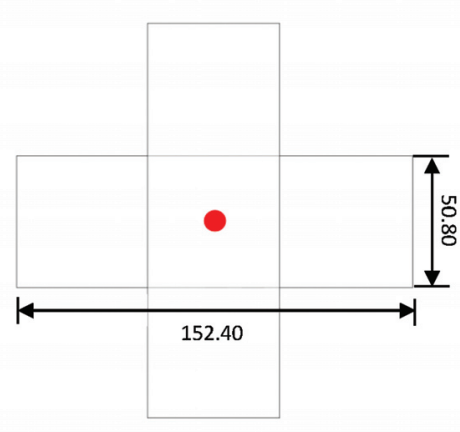

Fig. 2 - Test specimen dimensions: A - Tensile shear; $B$ - cross tension; $C$ - coach peel. Note: all units are in $\mathrm{mm}$.

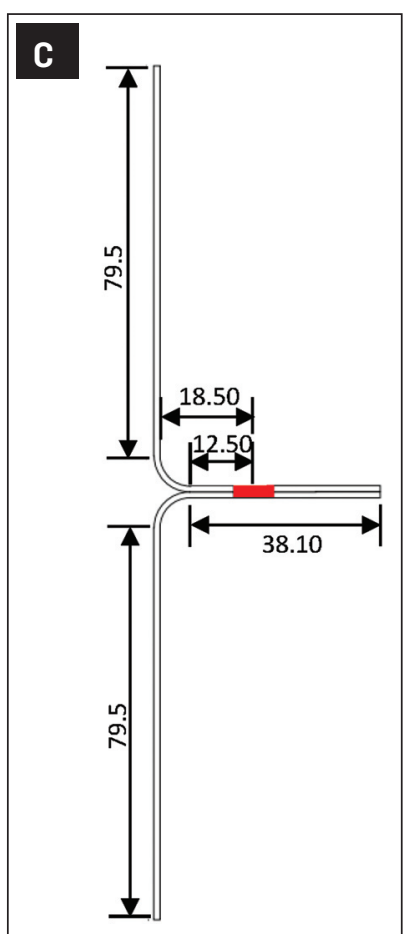

the electrode/sheet interface and the welding, which complicates the generation of heat in and around the weld, and causes variability in weld quality because the oxide layer is nonuniform. Owing to the high thermal and electrical conductivity of aluminum alloys, the contact resistance at the sheet/ sheet faying interface makes the primary contribution to forming a weld nugget. Unfortunately, the electrode/ sheet contact resistance generates excessive heat around the electrode, resulting in wear as well as a lack of consistency and robustness during spot welding (Ref. 9).

There are many factors that influence contact resistance in the RSW process, including the sheet surface condition, mechanical interactions, and welding schedule. Al Naimi and $\mathrm{Al}$ Saadi (Ref. 10) investigated the influence of surface pretreatment on the RSW quality of AA1050 sheets with three thicknesses and compared welding of the as-received sheet with the pretreated sheet by either pickling in $\mathrm{NaOH}$ or glass blasting. They pointed out that contact resistance was drasti- 
cally reduced by glass blasting, which removed the original oxide film and provided a rough surface to break down the oxide layer through asperity deformation. However, both pickling and glass blasting add an additional processing step, reducing productivity in practice.

Arrington (Ref. 11) twisted the electrode to remove the oxide film and the contaminants on the aluminum sheet surface before welding to improve electrode life and weld quality. However, this added time to the weld cycle to rotate the electrode, and added complexity to the robot programming to synchronize the electrode rotation with the weld gun movement.

To increase the electrode life, DeltaSpot, developed by Fronius, uses a continuous tape running between the electrode and sheet to improve welding efficiency by additional process heat that arises from both the internal and contact resistance of the process tape (Ref. 12). However, the continuous tape feed is a consumable that increases the processing cost. Crinon and Evans (Ref. 13) reported that even a small amount of induced sliding combined with pressure on specimens can displace surface films to produce a large increase in metalto-metal contact, which causes a dramatic reduction in contact resistance. Nevertheless, this concept is difficult to implement because the panels are generally fixed in position while the body-in-white (BIW) structure is assembled.

Luo and Ao (Ref. 14) studied a preheating treatment within the weld schedule designed to reduce the contact resistance at the faying interface by two orders of magnitude. However, this would drive considerable work to optimize welding parameters to meet the varied oxide films on the surface of commercial aluminum sheet combina-

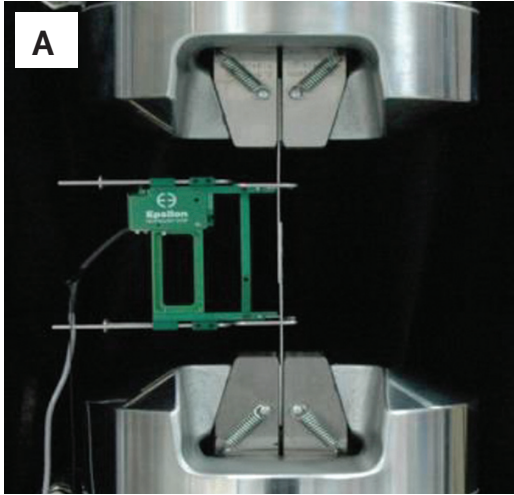

Fig. 3 - Photos of experimental setup (clamp, test specimen, extensometer, and coupon fixture for cross-tension testing) prior to application of load: A - Tensile shear; $B-$ cross tension; $C-$ coach peel.

tions. Moreover, they did not indicate whether preheating affected the electrode/sheet contact resistance, which is the primary reason for excessive electrode wear, surface expulsion, and inconsistent weld quality. Increasing the electrode weld face surface roughness is an unusual method to reduce the electrode/sheet interface contact resistance (Ref. 15). An electrode with a microtextured weld face, referred to as the textured electrode, was created by blasting with coarse grit using high-pressure air to obtain a surface roughness of $\mathrm{R}_{\mathrm{a}}=5$ $\mu \mathrm{m}$. However, replacing cutterbladestyle tip dressers with small grit blasters throughout the body shop is not a desirable solution to maintain on a manufacturing shop floor.

The GM-patented Multi-Ring Domed (MRD) (Refs. 16, 17) electrode was created by using a uniquely designed dressing blade to produce a series of concentric ridges/grooves on the electrode weld face. The individual ring is intended to plastically deform and penetrate the aluminum oxide surface. Multiple rings in action can fracture the surface oxide by produc-
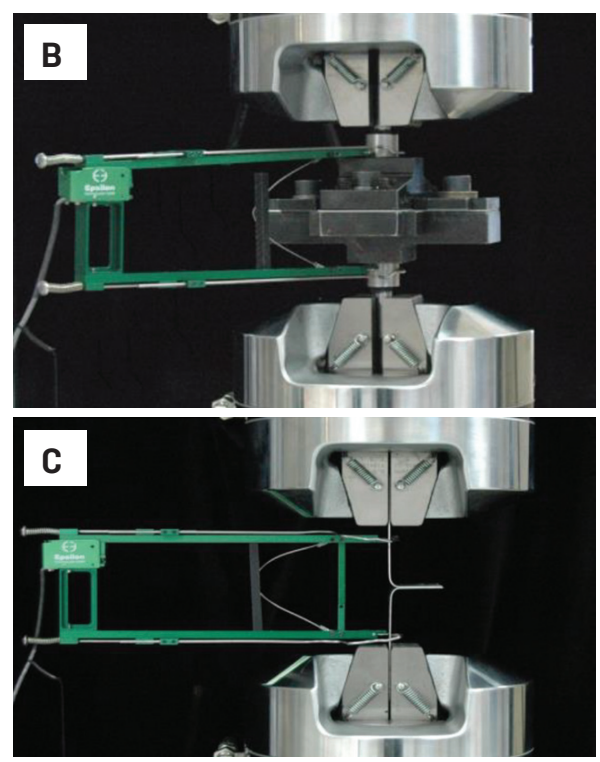

ing alternating patterns of tensile and compressive surface strains. Fracture of the surface oxide allows for intimate contact between the electrode and aluminum alloy substrate, thereby reducing the electrode/sheet contact resistance and improving heat transfer between the electrode and sheet. As a result, heat distribution during spot welding changes tremendously.

This paper explores, through microstructural analysis and mechanical property testing, the effect of electrode weld face topography upon the resistance spot welding of $1.2-\mathrm{mm}$ 6022-T4 aluminum sheets welded to itself. For comparison, a common electrode geometry with three types of weld face topographies were systematically studied: A textured electrode and a MRD electrode employing two ring heights, Ring $\mathrm{H} 1$ and $\mathrm{H} 2$.

\section{Experimental Procedure}

Aluminum alloy AA6022-T4 sheets of $1.2 \mathrm{~mm}$ thickness were the basis for this study. The nominal chemical composition and mechanical properties for

Table 1 - Chemical Composition and Mechanical Properties of AA6022-T4

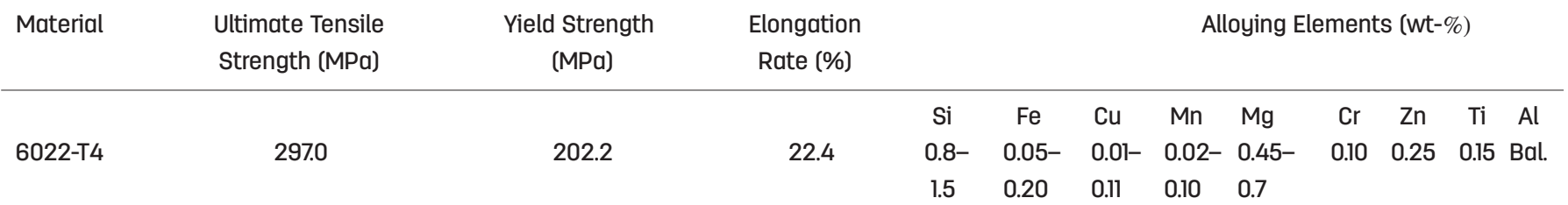



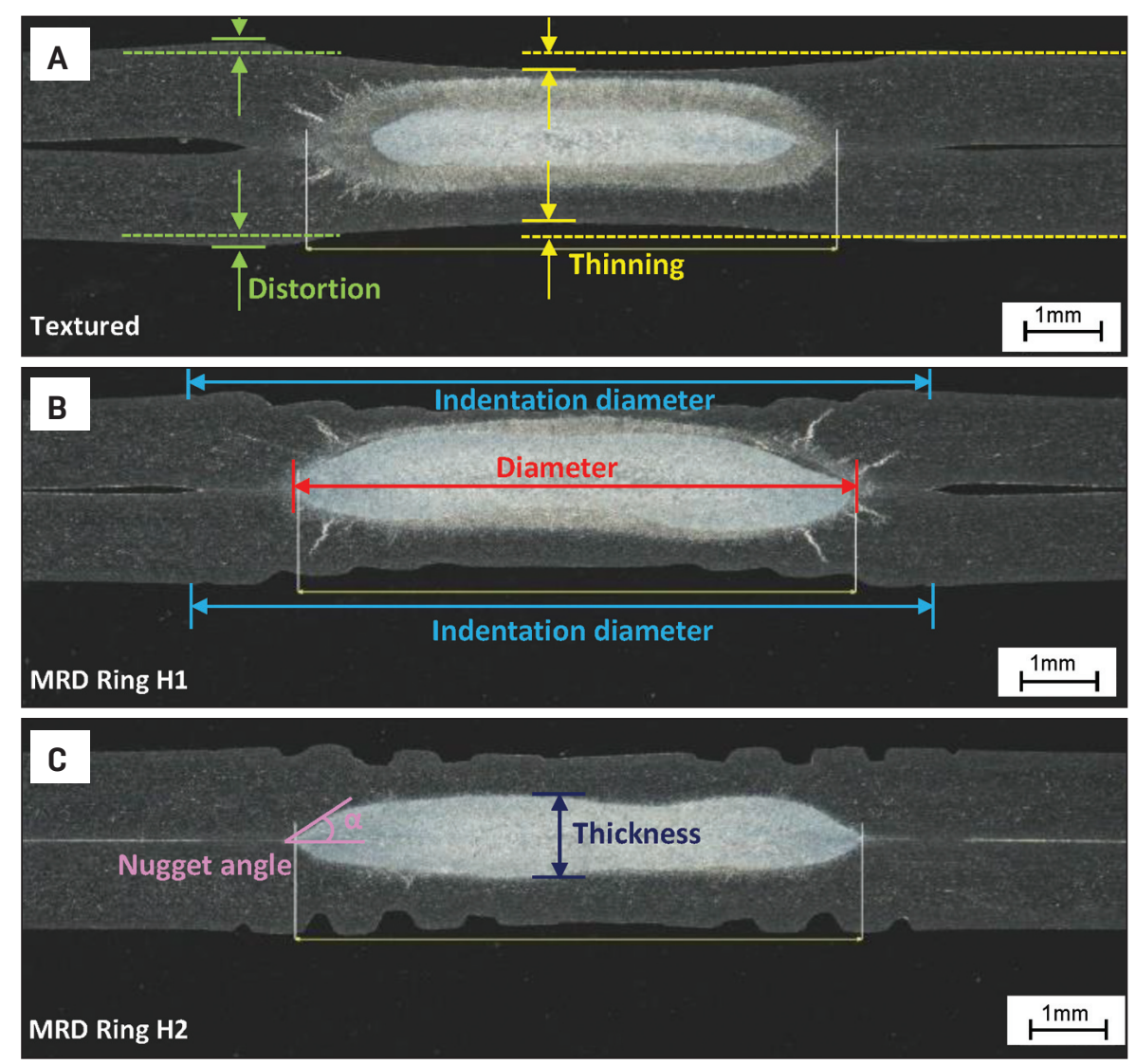

Fig. 4 - Typical polished cross sections of the RSW nuggets for various electrodes: A - Textured; B - MRD Ring HI; C - MRD Ring H2. Graphical representation of the experimental weld characteristics are included.

Table 2 - Indentation Diameters for the Top and Bottom Indentations (mm)

\begin{tabular}{cccc} 
Electrodes & Textured & MRD Ring H1 & MRD Ring H2 \\
\hline $\begin{array}{c}\text { Indentation } \\
\text { diameter }\end{array}$ & $7.39 / 7.39$ & $7.94 / 7.72$ & $7.38 / 7.87$ \\
\hline
\end{tabular}

this alloy are provided in Table 1 . No surface cleaning procedures were conducted, and all testing was completed with sheets in the as-received condition.

All electrodes were conventional C15000 with a nominal composition of $\mathrm{Cu}-0.15$ wt-\% $\mathrm{Zr}$. The textured and MRD Ring H1 electrodes had a body diameter of $19.05 \mathrm{~mm}$ and a $12-\mathrm{mm}$ weld face, while the MRD Ring H2 electrode was somewhat smaller at 16mm outer diameter with a $10-\mathrm{mm}$ diameter weld face. All electrode weld faces were dressed to a $25-\mathrm{mm}$ radius of curvature. The various electrode faces in this body of work were characterized using a Keyence model VR3000 laser confocal 3D imaging system - Fig. 1. According to standard
ISO 4287:1997 (Ref. 18), the profile arithmetic average error $R_{a}$ was chosen to represent surface roughness. The textured electrode weld face had an approximate $\mathrm{R}_{\mathrm{a}}$ of $5 \mu \mathrm{m}-$ Fig. $1 \mathrm{~A}$. The 12-mm-diameter weld face of the MRD Ring H1 (Fig. 1B) enabled five relatively shallow rings (average ring height of $80 \mu \mathrm{m}$ ) to be dressed, while the smaller weld face of the MRD Ring H2 (Fig. 1C) had four, although these were taller rings (average ring height of $200 \mu \mathrm{m}$ ).

The welding system contained both an inverter direct current (DC) and a single-phase alternating current (AC) weld control. Transformers included a medium-frequency DC (MFDC) unit rated at $170 \mathrm{kVA}, 13 \mathrm{~V}$ maximum, and an AC unit rated at $400 \mathrm{kVA}, 29 \mathrm{~V}$ maximum. The actual weld schedules followed the Conditioning, Shaping, and Sizing (CSS) weld schedule concept (Ref. 19), which is listed below. Preheat as well as squeeze and hold times were kept constant for all welds, and a 700-lb electrode clamping force was applied. Slight changes in the peak current level of the sizing portion of the CSS weld schedule were necessary to accommodate the changes of the electrode face design and achieve the targeted 5.5-mm-diameter weld nugget.

- Preheat - $700 \mathrm{lb}: 40 \mathrm{~ms}$ at $6.9 \mathrm{kA}$ rms, cool $10 \mathrm{~ms}$

- Textured electrode - 700 lb: weld $101 \mathrm{~ms}$ at $27.5 \mathrm{kA}$ rms, hold $100 \mathrm{~ms}$

- MRD Ring H1 - 700 lb: weld 101 $\mathrm{ms}$ at $27.8 \mathrm{kA}$ rms, hold $100 \mathrm{~ms}$

- MRD Ring H2 lap shear, coach peel - $700 \mathrm{lb}$ : weld $101 \mathrm{~ms}$ at $27.5 \mathrm{kA}$ rms, hold $100 \mathrm{~ms}$

- MRD Ring H2 lap shear, cross tension — $700 \mathrm{lb}$ : weld $101 \mathrm{~ms}$ at $27.8 \mathrm{kA}$ rms, hold $100 \mathrm{~ms}$

Metallurgical analysis was performed on tested and untested specimens by cross sectioning along the centerline of the weld nugget. Specimens were hot mounted in resin powder and mechanically ground and polished. For metallographic analyses, the specimens were etched using Keller's reagent (95 mL water, $2.5 \mathrm{~mL}$ $\mathrm{HNO}$, $1.5 \mathrm{~mL} \mathrm{HCl}$, and $1.0 \mathrm{~mL} \mathrm{HF}$ ). All samples were dried and placed in a desiccator after cleaning by deionized water and ethanol. Macrographs of the specimens were imaged under a Leica digital optical microscope (S8 APO for low magnification, and DM4M for higher magnification).

Finer scale investigation was completed with a Zeiss Auriga scanning electron microscope (SEM). Chemical composition analysis of the microstructural constituents was performed with a Zeiss Auriga SEM energy-dispersive spectroscopy (EDS) system.

The quasistatic tensile-shear, coach-peel, and cross-tension testing of the specimens (Fig. 2) was performed on a SUNS electromechanical test frame at a cross-head speed of 5 $\mathrm{mm} / \mathrm{min}$ (Fig. 3) for photos of the experimental load train for each test. A minimum of seven replicates were completed for each condition. 


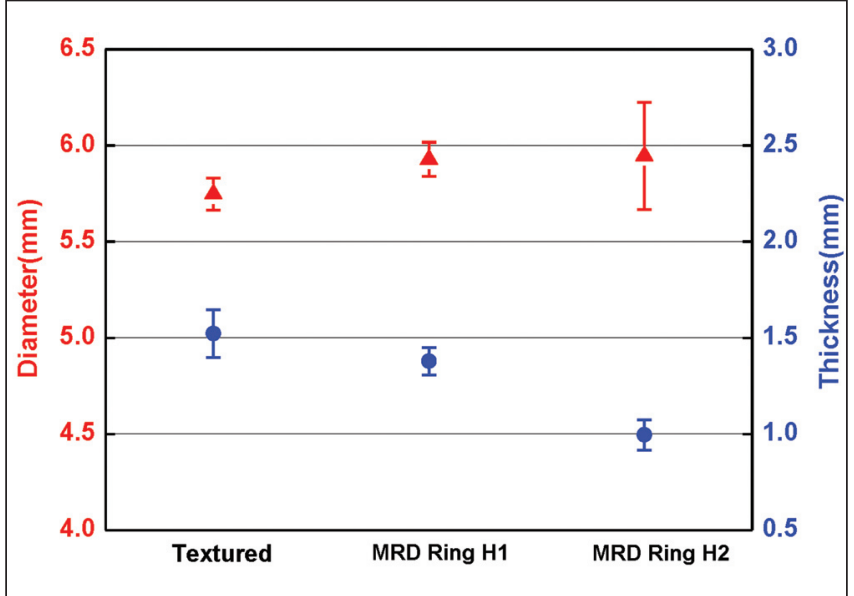

Fig. 5 - Average weld nugget diameter and nugget thickness measurements (triangles and circles, respectively) as a function of electrode design.

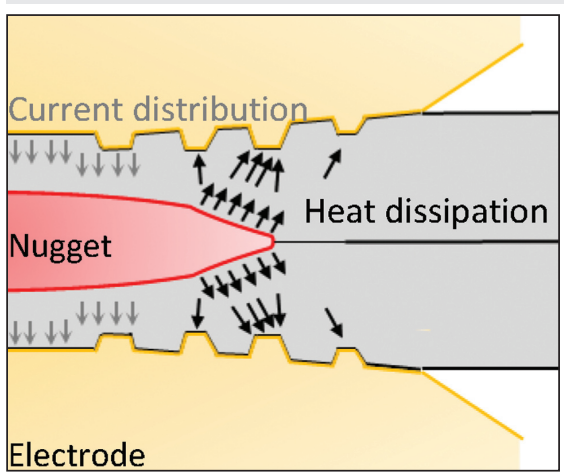

Fig. 7 - Conceptual model of current distribution and heat dissipation with a MRD electrode.

\section{Results and Discussion}

\section{Weld Morphology}

Figure 5 is a series of photomicrographs of the 1.2-mm-thick AA6022-T4 to AA6022-T4 RSW specimen cross section along the centerline of the weld parallel to the coupon length and subjected to metallurgical preparation for each of the electrode designs. Indentations on the sheet surface from the MRD electrode are evident in Fig. 4B and $C$. The weld from the textured electrode (Fig. 4A) clearly exhibits two distinct weld nugget zones and a greater amount of distortion. Welds appear offset toward the upper sheet or positive electrode in Fig. 4A and B, while eutectic stringers (i.e., whiskers) rich in alloy content were observed on the periphery of the weld nugget in the same.

The quantification of the effect of the electrode weld face design on

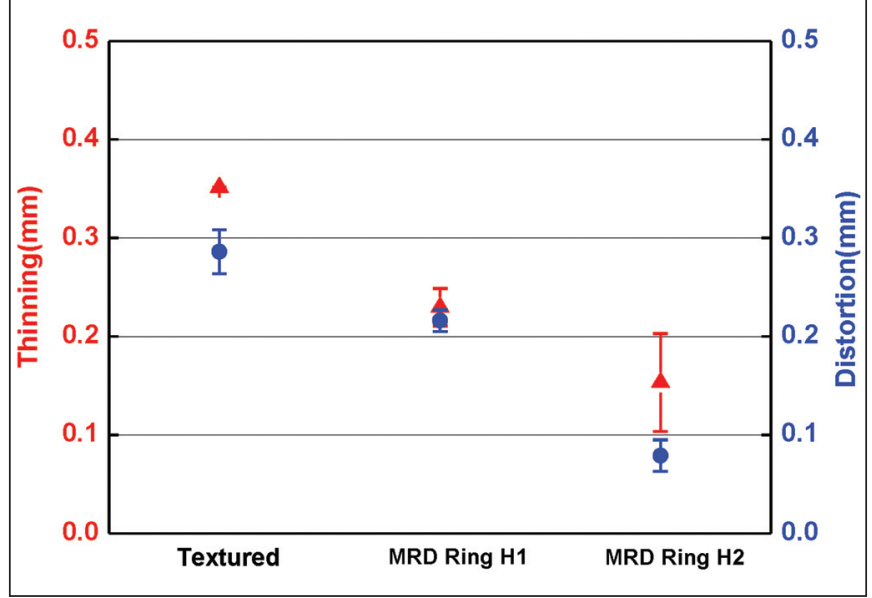

Fig. 6- Average weld thinning and distortion measurements (triangles and circles, respectively) as a function of electrode design.
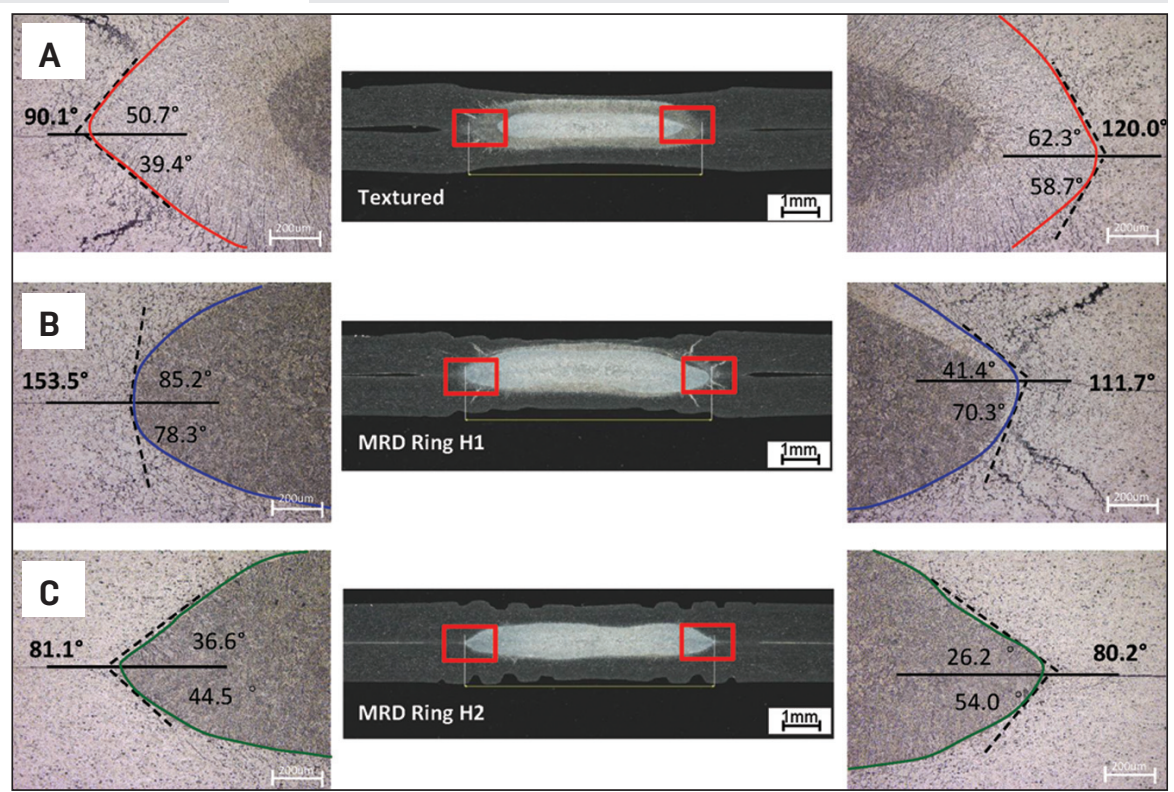

Fig. 8 - Representative weld nugget angles formed at the faying interface from different electrode geometries: A - Textured; B - MRD Ring HI; C - MRD Ring H2. nugget diameter and thickness are presented in Fig. 5, and on thinning and distortion in Fig. 6. Figures 5 and 6 show that, compared to the MRD electrode, weld nuggets produced using the textured electrode are slightly smaller in diameter, and have greater penetration or thickness, greater thin-
Table 3 - EDS-Based Chemical Composition at Various Points of the 'Eyelash' Microstructure Elements (wt-\%)

\begin{tabular}{cccccc}
$\begin{array}{c}\text { Spectrum } \\
\text { Nominal Value }\end{array}$ & $\mathrm{Al}$ & $\mathrm{Si}$ & $\mathrm{Mg}$ & $\mathrm{Fe}$ & $\mathrm{Cu}$ \\
\hline 1 & & $0.8-1.5$ & $0.45-0.7$ & $0.05-0.2$ & $0.01-0.11$ \\
\hline 2 & 84.3 & 12.5 & 0.8 & - & 2.4 \\
3 & 87.2 & 7.8 & 0.8 & 2.0 & 2.2 \\
4 & 77.8 & 18.4 & 1.0 & - & 2.8 \\
& 70.7 & 21.2 & 2.2 & 1.3 & 4.6 \\
\hline
\end{tabular}




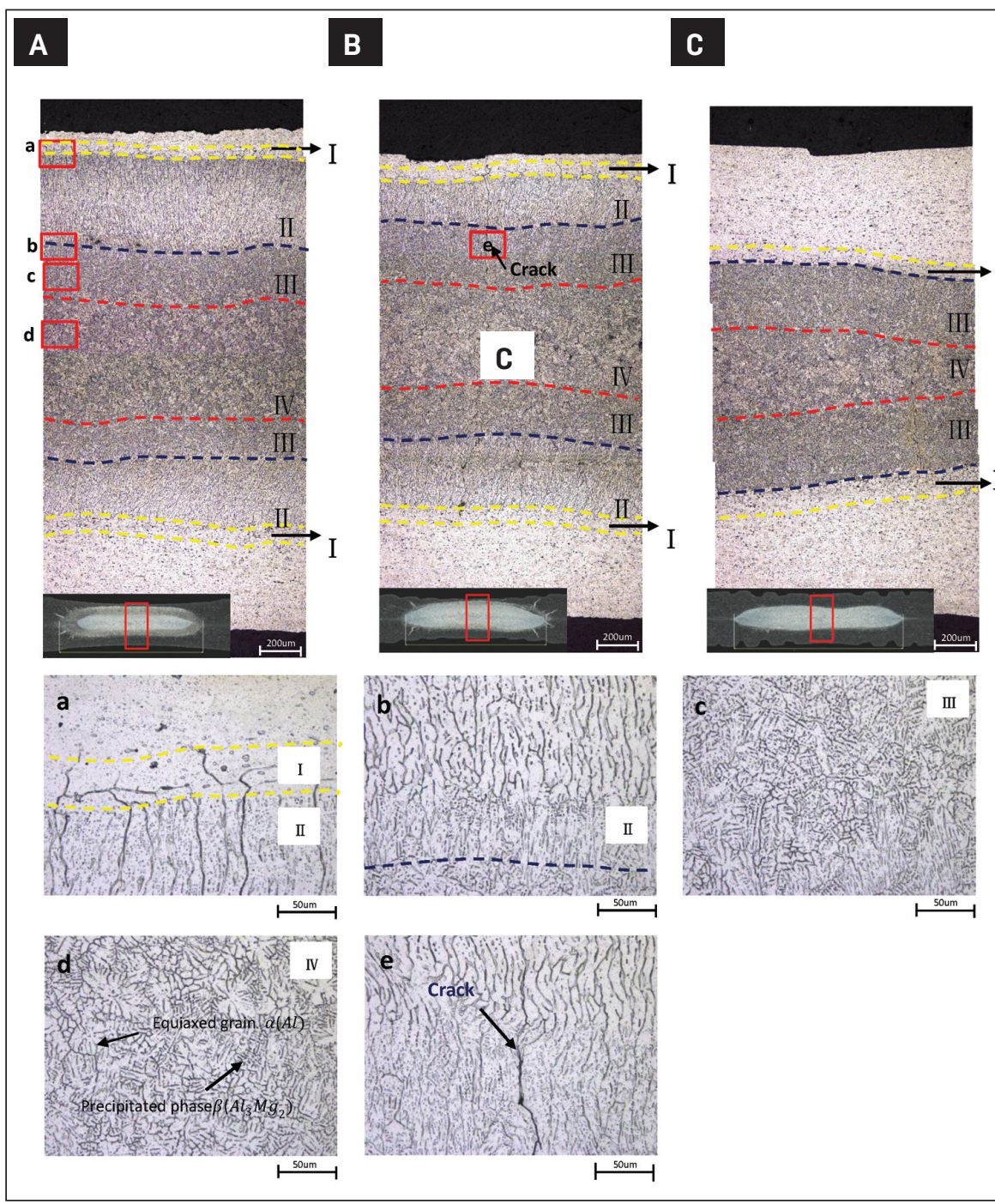

Fig. 9-Weld nugget microstructures from various electrode geometries: A - Textured; $B-M R D$ Ring Hl; $\mathrm{C}-M R D$ Ring $\mathrm{H} 2$. The weld nugget zones identified are the following: I - partially melted zone (PMZ), II - coarse columnar zone (CCZ), III - fine dendritic zone (FDZ), and IV - equiaxed zone (EZ). The five photomicrographs labeled $a-d$ are higher magnification photos of specific areas highlighted by red boxes in Fig. 9A, and photomicrograph e is from Fig. 9B.

ning, and increased distortion. The textured electrode weld face does not penetrate as deeply into the upper sheet surface as the MRD Rings. The contact diameters for the welds in Fig. 4 are listed on Table 2 .

These dimensions show that the average contact area for the textured electrode was somewhat smaller than that for both of the MRD electrodes. This effect was caused by the protruding rings of the MRD electrode, which acted to quickly spread current out during welding as successive rings came into contact with the sheet surface. Effectively, the MRD electrode operated as if it had less curvature (i.e., a higher radius of curvature) than the textured electrode. This produced higher current densities for the textured electrode compared to the MRD electrodes. The higher current density created more heat within the weld, which enabled the weld nugget to grow out toward the electrode, accounting for the greater weld nugget penetration or thickness. In addition, the smaller effective radius of the curvature of the textured electrode was more effective at moving material laterally, accounting for the greater distortion and larger notch roots, which can affect mechanical performance of the joint.

The penetration of the rings of the MRD electrodes with its flatter- effective weld face created a broader distribution of current - Fig. 7. This effect was accentuated with the greater ring height of MRD Ring H2 compared to MRD Ring H1. The larger contact area (see Table 2) and greater penetration of the MRD Ring H2 also created greater cooling at the weld perimeter, which acted to reduce the angle formed by the nugget at the faying interface compared to MRD Ring H1 (compare Fig. 8B and $C$, respectively).

\section{Weld Microstructure}

Figure 9 presents photomicrographs of weld microstructures developed by each of the three electrode face designs. The local solidification conditions ( $\mathrm{G}=$ temperature gradient at the liquid/solid interface, and $\mathrm{V}=$ growth rate) at the liquid/solid interface is a function of the melt pool geometry and position of the liquid/ solid interface, which themselves are functions of the electrode face design. For the purpose of this discussion, we define four microstructural zones based upon the resulting solidified crystal structure starting from the base metal to the center of the weld nugget: I partially melted zone (PMZ), II coarse columnar zone (CCZ), III — fine dendritic zone (FDZ), and IV equiaxed zone (EZ) (Refs. 20-22).

The PMZ located just outside of the weld nugget boundary for all welds was characterized by relatively large recrystallized grains. This area exceeded the solidus temperature, but never fully reached the liquidus temperature during welding. Local grain boundary melting was visible in this area.

The CCZ was most prevalent for the textured electrode. It was produced adjacent to the nugget boundary. The CCZ occurs under conditions where decreasing current density caused by electrode indentation cannot provide sufficient heat to continue weld nugget growth. Weld nugget growth stalls, and as current density falls further, nugget recession occurs as solidification begins while weld current is still flowing. The shallow thermal gradients present under these conditions resulted in the formation of a coarse, columnar weld nugget structure with rejection of solute into the remaining molten pool. The textured electrode commonly produces this effect be- 

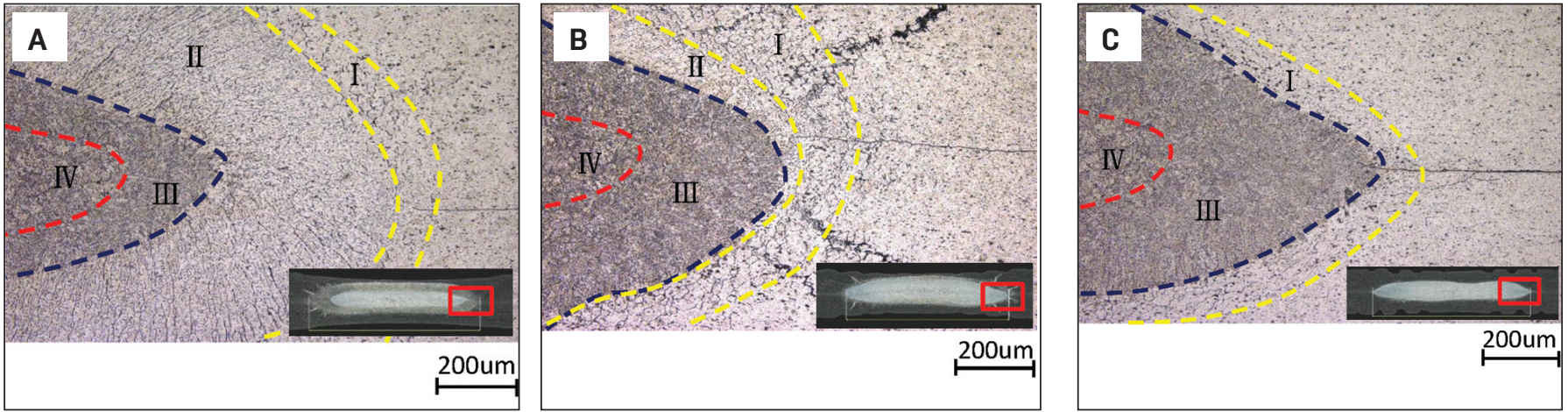

Fig. 10 - Photomicrographs of weld microstructure and associated zone at weld nugget notch area welded by A - Textured; B MRD Ring HI; C - MRD Ring H2. Zones defined as I: PMZ, II: CCZ, III: FDZ, and IV: ECZ.

cause it has a very large change in current density from the beginning to the end of the weld schedule, i.e., contact area is very small when current flow initiates, and it expands rapidly. In contrast, the MRD electrode has a larger contact area during initial current flow, which is caused by engagement of the protruding rings.

It was also observed that when the weld nuggets were offset toward the typically hotter positive electrode, the width of the CCZ on this side of the weld nugget was greater than that for the $C C Z$ on the opposite side of the weld nugget, i.e., toward the negative electrode. Having the molten pool closer to the cooling effect of the electrode produced recession or local nugget solidification. The MRD Ring H2 exhibited negligible CCZ. In this case, the weld nugget was thin and further away from the cooling effect of the electrode weld face, and thus was less susceptible to recession. The MRD Ring $\mathrm{H} 1$ did exhibit a CCZ, but the size was somewhere in between that of the textured electrode and MRD Ring H2. Note that the weld schedule used in this study was designed for use with the MRD H2 tall-ring electrode, and thus was designed with the appropriate slope and pulsations to minimize recession.

Next to the CCZ is the FDZ. This zone is created by formation of a steep thermal gradient between the watercooled welding electrode and weld nugget after termination of weld current. A fine-grained, harder dendritic structure is created. Eventually, as cooling progresses, an equiaxed dendritic zone is created. This occurs as the nugget is supercooled and dendrites solidify within the molten metal pool. This zone tends to be higher in alloy

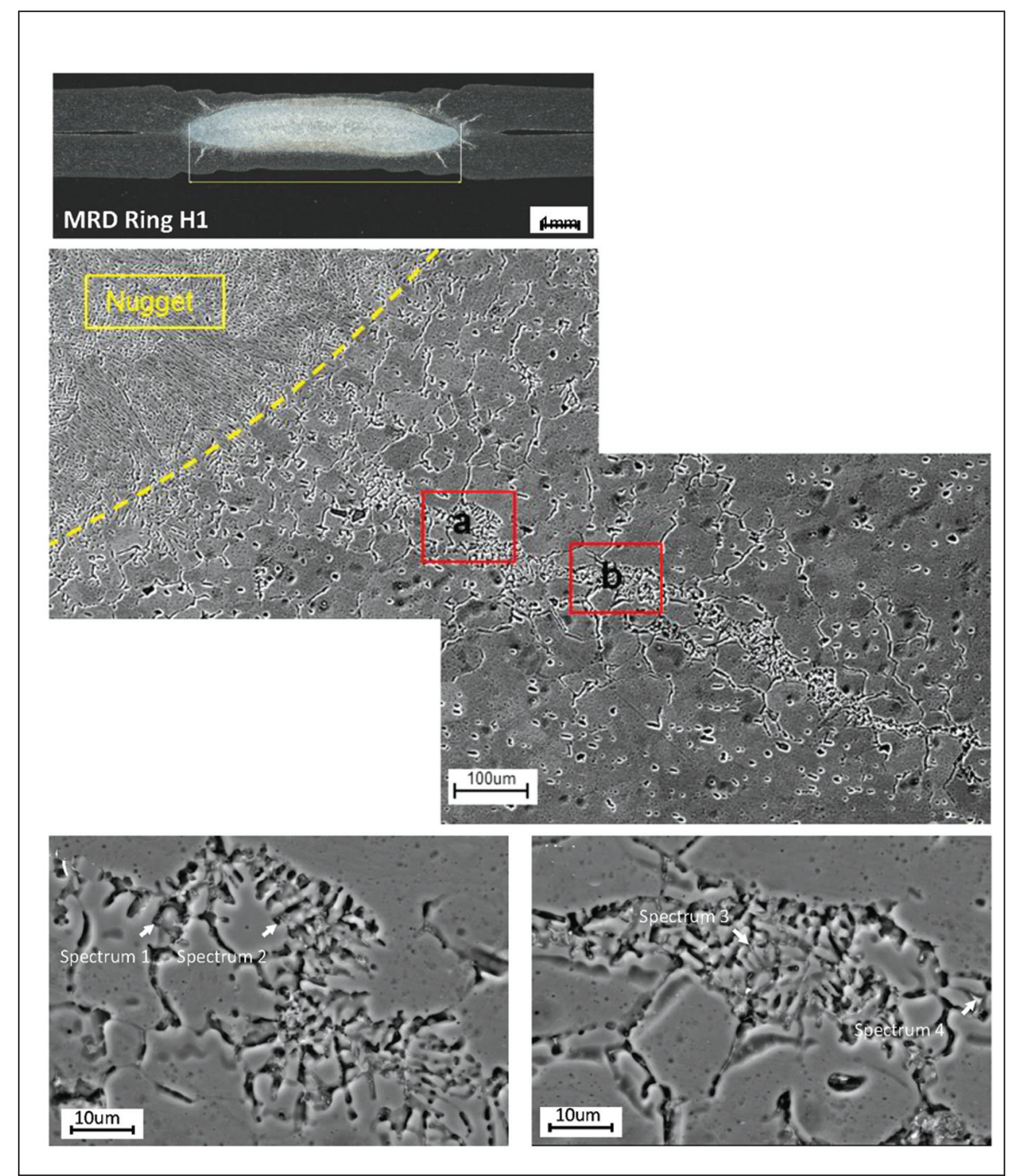

Fig. 11-Micromorphology of 'eyelashes' structure by SEM.

content due to rejection of alloy content from the CCZ as well as the FDZ and also shows precipitated phases.

\section{Eutectic Stringers}

The metallographic study also re- vealed 'eyelash'-like microstructures emanating from the weld nugget and progressing radially outward through the heat-affected zone (HAZ) in the vicinity of the weld notch area for welds produced by Textured and MRD Ring H1 electrodes - Figs. 4, 10, and 11. 

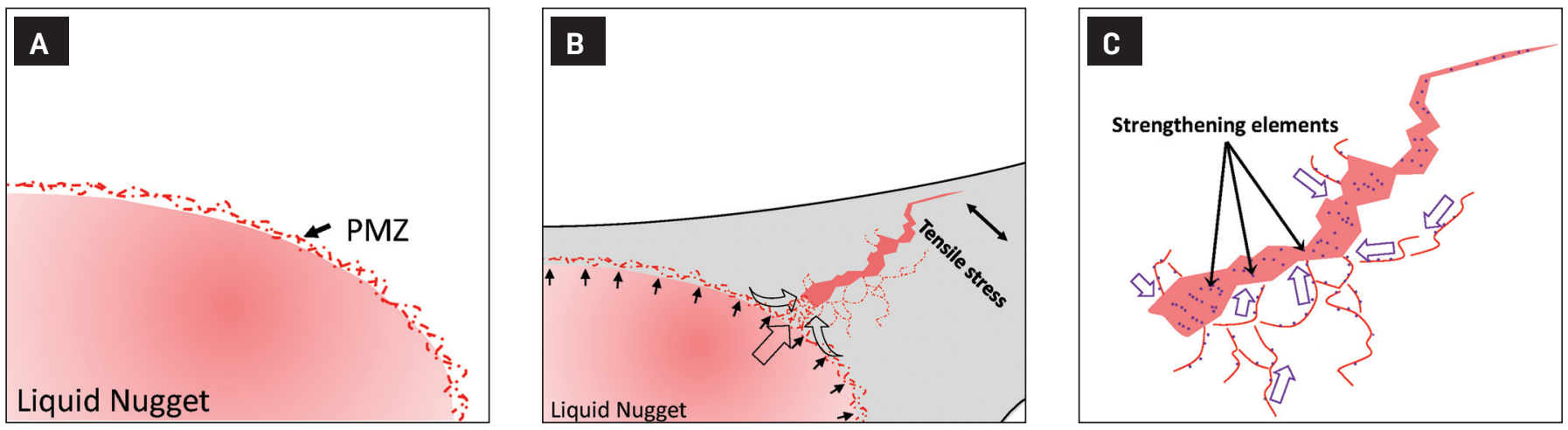

Fig. 12 - Schematic illustration of 'eyelash' formation mechanism: A - Partial melting in HAZ; B - cracking filling; C - alloy element segregation.

This phenomenon was not observed for welds produced with the MRD Ring H2 electrodes. Microstructural analysis identified a recrystallized microstructure with intergranular characteristics and dendritic morphology. This is considered to be subsolidus grain boundary liquation, which happens at temperatures generally above the eutectic temperature but below the equilibrium solidus temperature, and as such are referred to here as eutectic stringers.

It is known that rapid heating rates can cause local melting of grain boundary precipitants, and/or segregated alloy content. The EDS revealed segregation of alloying elements such as as $\mathrm{Si}, \mathrm{Mg}, \mathrm{Fe}$, and $\mathrm{Cu}$ at the grain boundaries (Table 3). Possible lowmelting eutectics in Al-Mg-Si alloys, which may have contributed to the liquation, are listed in Table 4.

Another factor is the sharper effective radius of curvature for the textured and MRD-H1 electrodes compared to the MRD-H2 electrodes. This may induce thermomechanical loading, which opens up the grain boundaries having grain boundary liquation. During the rapid cooling process, the metal contracted, developing tensile stress along the tangent of isotherms in the HAZ, which facilitates the opening up of grain boundaries with low-melting point constituents - Fig. 12

The liquid in the nugget would eject under high pressure (i.e., loading from the electrode) through the mushy PMZ to fill up cracks in the HAZ before solidification was complete (Refs. 23-28). This may explain why the textured and MRD-H1 electrodes, which exhibited an effectively sharper radius compared to the MRD-H2 electrode, is associated with eutectic stringers while the MRD Ring H2 is not.

\section{Mechanical Properties}

A large number of factors that include the nugget diameter, sheet thinning, nugget porosity and porosity

Table 4 - Possible Low-Melting Eutectics in Al-Mg-Si Alloys

Eutectics

$\mathrm{Al}-\mathrm{Mg}_{2} \mathrm{Si}$

Melting Temperature $\left({ }^{\circ} \mathrm{C}\right)$

$$
\text { Al-Si }
$$

$\mathrm{Al}-\mathrm{Mg}_{2} \mathrm{Si}-\mathrm{Si}$

$\mathrm{Al}-\mathrm{Mg}_{2} \mathrm{Si}-(\mathrm{FeMn})_{3} \mathrm{Si}_{2} \mathrm{Al}_{15}-\mathrm{Si}$

$\mathrm{Al}-\mathrm{Mg}_{2} \mathrm{Si}-\mathrm{FeMg}_{3} \mathrm{Si}_{6} \mathrm{Al}_{8}-\mathrm{Si}$

$\mathrm{Al}-\mathrm{Mg}_{2} \mathrm{Si}-(\mathrm{CrFe})_{4} \mathrm{Si}_{4} \mathrm{Al}_{13}-\mathrm{Si}$

$\mathrm{Al}-\mathrm{CuAl} \mathrm{I}_{2}-\mathrm{Mg}_{2} \mathrm{Si}$

$\mathrm{Al}-\mathrm{Cu}_{2} \mathrm{Mg}_{8} \mathrm{Si}_{6} \mathrm{Al}_{5}-\mathrm{CuAl}-\mathrm{Si}$ distribution, microcracking, local microstructural features, notch root geometry as well as other features, control the mechanical performance of RSW joints. In this current work, three test geometries were investigated under static loading: tensile shear, cross tension, and coach peel. Subsequent work will investigate fatigue loading of these geometries.

Tensile shear. Figure 13A and B present tensile-shear strength and weld nugget diameter, as well as the energy at peak load for tensile-shear samples as a function of electrode face design. The average peak load and nugget diameter exhibited no statistically significant dependence upon the electrode face design, and all fracture modes were interfacial. There was no evidence of expulsion.

There was a noticeable difference in crack path between the textured and MRD electrodes. Figure 15 reveals that for textured electrode specimens, which experienced a significant amount of recession and CCZ formation, the crack initiated at the perimeter of the nugget at the faying interface within the CCZ, and propagated along the length of the grains in the CCZ boundary. It then changed paths upon meeting the FDZ to progress along the CCZ/FDZ boundary. Finally, both penetrated into the FDZ/EZ and combined for complete fracture of the specimen.

For specimens welded with MRD Ring $\mathrm{H} 1$ and $\mathrm{H} 2$ electrodes, recession and CCZ formation was much more limited. This affected weld nugget fracture during tensile-shear testing. The cracks propagated through the FDZ, which formed a shell along the perimeter of 
A

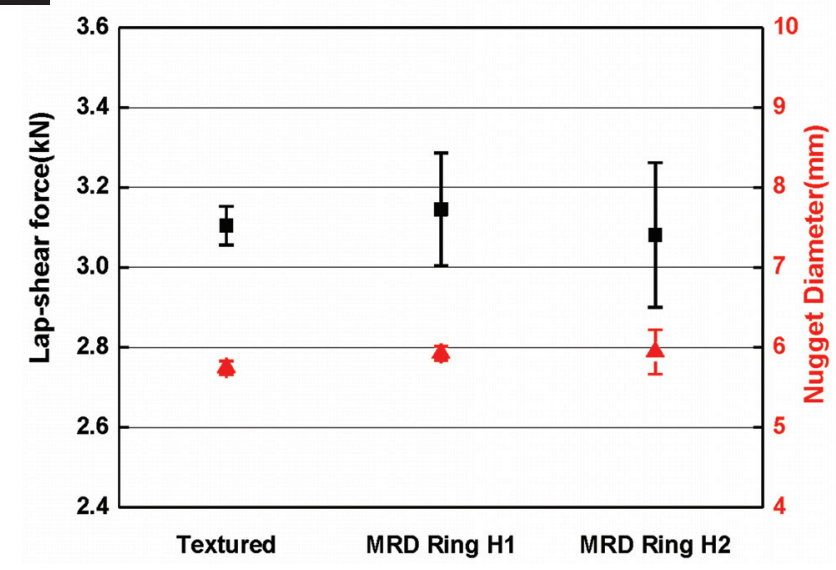

B

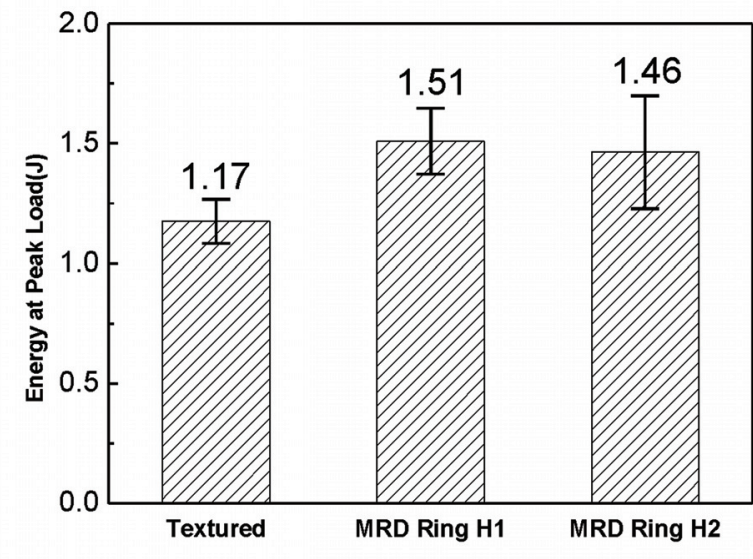

Fig. $13-A-$ Tensile-shear strength and weld nugget diameter; B - energy at peak load as a function of electrode face design (textured, MRD Ring $H 1$, and MRD Ring $\mathrm{H} 2$ ).

the nugget at the faying interface, followed by the EZ - Fig. 14. This finedendritic area appeared to absorb more energy compared to the CCZ structure, as shown by the data in Fig. 13 for textured and MRD electrodes.

Cross tension. Figure 15 presents cross-tension strength and weld nugget diameter as a function of electrode face design. The average nugget diameter exhibited no statistically significant dependence upon electrode face design. However, the average peak load for the MRD Ring H2 was significantly lower than that for either the textured or MRD Ring $\mathrm{H} 1$ electrodes. The fracture modes of all electrode geometries were button pull-out. However, two propagation paths were observed. The textured specimens (Fig. 16A) exhibited crack initiation and propagation along the larger grains of the $C \mathrm{CZ}$ similar to the tensile-shear specimens. The crack then proceeded into the EZ until the bending of the coupon forced a change in the preferred crack path direction, perpendicular to the sheet surface. For both MRD Ring H1 and H2 electrodes, the crack did not penetrate the FDZ. This is most likely due to the much finer dendritic structure providing greater strength than the CCZ. The path followed along the weld nugget periphery where the strength was reduced in the PMZ (Fig. 16B and C) until the point of mechanical loading due to bending of the coupon, which forced a change in the preferred crack path direction perpendicular to the sheet surface.

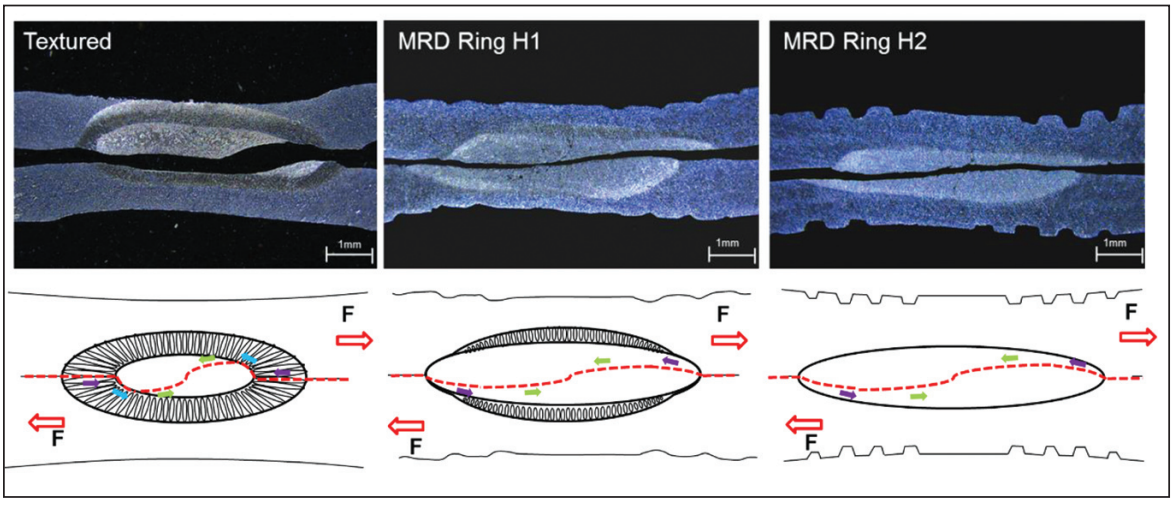

Fig. 14 - Crack path within fractured tensile-shear specimens as a function of weld nugget and electrode face design (textured, MRD Ring Hl, and MRD Ring H2).

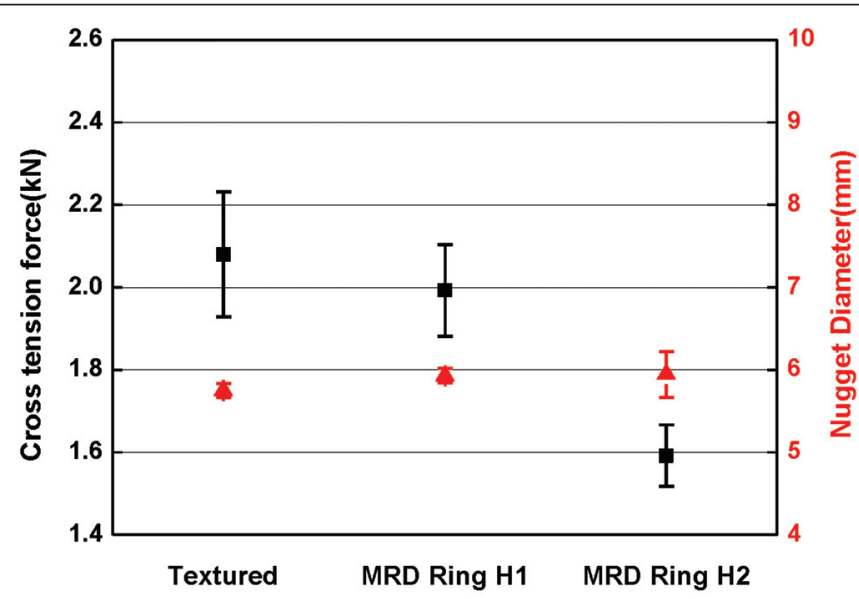

Fig. 15 - Cross-tension strength and weld nugget diameter as a function of electrode face design (textured, MRD Ring $\mathrm{Hl}$, and MRD Ring H2).

The reduced cross-tension strength for specimens welded by the MRD Ring $\mathrm{H} 2$ electrode is related to the weld nugget structure produced at the faying interface. The weld nugget had a shallow angle at the faying interface when using the MRD Ring H2, thus there was a more direct crack path that 

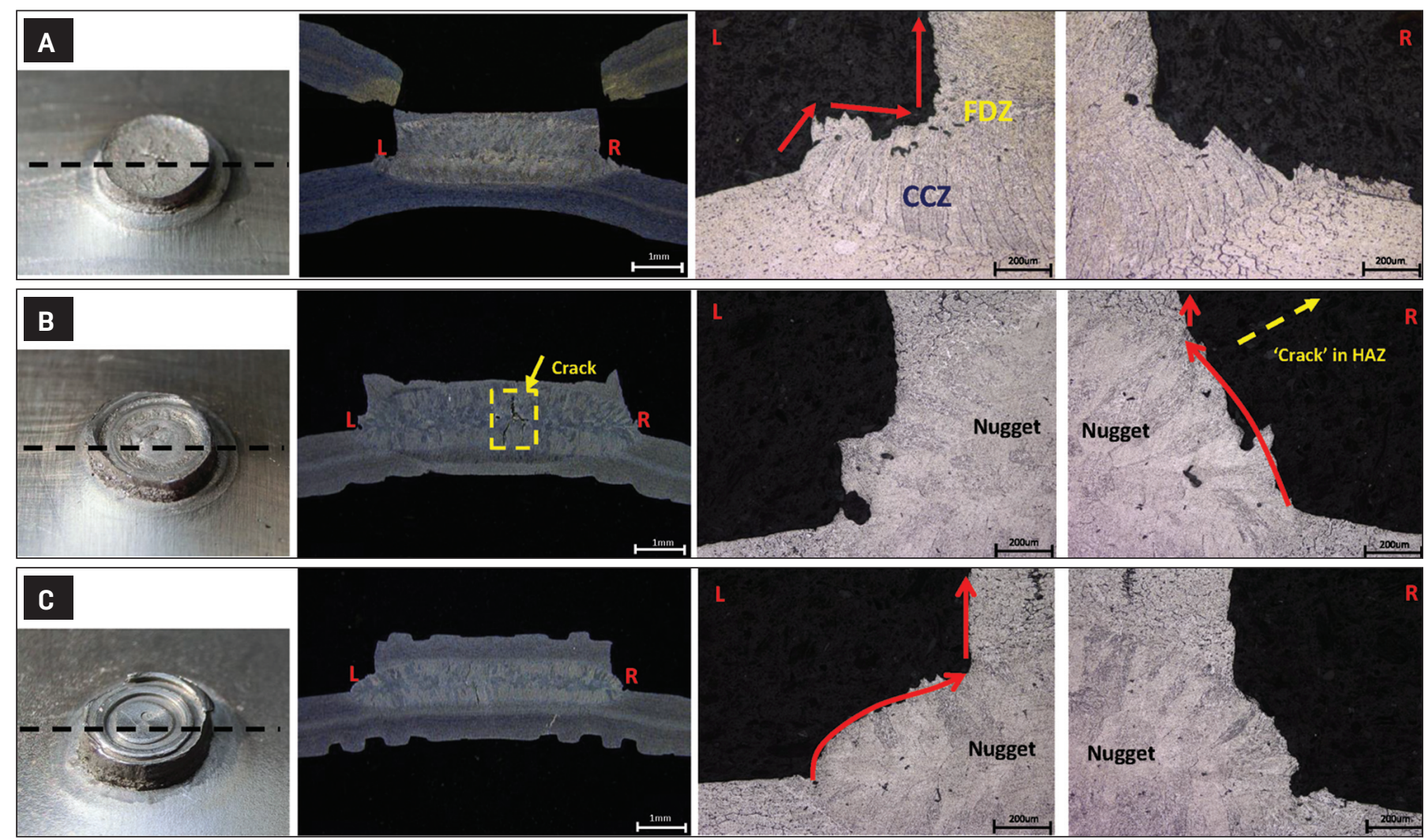

Fig. 16 - Crack path within fractured cross-tension specimens as a function of electrode face design: A - Textured; B - MRD Ring $\mathrm{HI}$; C - MRD Ring H2.

would have facilitated propagation and a lower cross-tension strength because the weld nugget diameters were comparable. Furthermore, the MRD Ring H2, having a greater ring height, also penetrated deeper into the substrate, such that as the crack propagated along the $\mathrm{PMZ}$ and changed direction as it moved beneath a ring indentation, there was a shorter distance for the crack to travel through the substrate (Fig. 17C), and ultimately fractured in the groove left by the ring.

Coach peel. Figure 18 presents coach-peel strength and weld nugget diameter as a function of electrode face design. The average nugget diameter exhibited no statistically significant dependence upon electrode face design. The average peak loads for all three sets of tests fell within their respective error bands. In general, the load displacement curve reached an initial peak followed by a load drop, which is the point of crack initiation. For MRD Ring H2, the load then increased slightly as crack propagation proceeded around the weld nugget until a second peak load was reached, after which the load dropped and the coupon fractured. All coupons fractured via button pullout mode.

Figure 19 shows the crack paths observed for coach-peel specimens. All three electrode designs produced button pullout. However, the crack paths were somewhat different. Both MRD electrodes produced the FDZ at the perimeter along the faying interface. This stronger structure was able to deflect the crack and form weld buttons during coach-peel testing. Welds made with the textured electrode behaved differently. The cracks first penetrated the outer, weak CCZ (Fig. 19A) and were then deflected by the stronger FDZ structure within the nugget to form a weld button.

Specimens welded by the MRD Ring H1 exhibited a somewhat higher coachpeel strength than either the textured or MRD Ring H2 electrode. The MRD Ring H1 weld nugget microstructure (Figs. 10 and 19B) is a good compromise between the large columnar dendritic region of the textured electrode weld (which favors easy crack growth along the columnar grain boundaries and then into the fine-dendritic zone - Fig. 19A), and the flatter weld nugget creat- ed by the MRD Ring H2 (which facilitates initial crack propagation along the PMZ - Fig. 19C). Neither the 'eyelash' microstructure in the HAZ, nor the cracks within the weld nugget, influenced crack path.

\section{Summary and Future Work}

This paper explores, through microstructural analysis and mechanical property testing, the effect of electrode face design upon the resistance spot welding of 1.2-mm-thick 6022-T4 aluminum sheet welded to itself. For each of the electrode designs, crosssectioned samples were made to measure the nugget diameter, thickness, angles, weld thinning, distortion, and contact diameter. This was supplemented by mechanical tests, including tensile shear, cross tension, and coach peel, performed on welds from each of the three electrode geometries.

The textured electrode responds as if it had a sharper radius of curvature compared to the MRD electrodes because of greater penetration, thinning, and distortion. The textured electrode also exhibited the largest CCZ struc- 

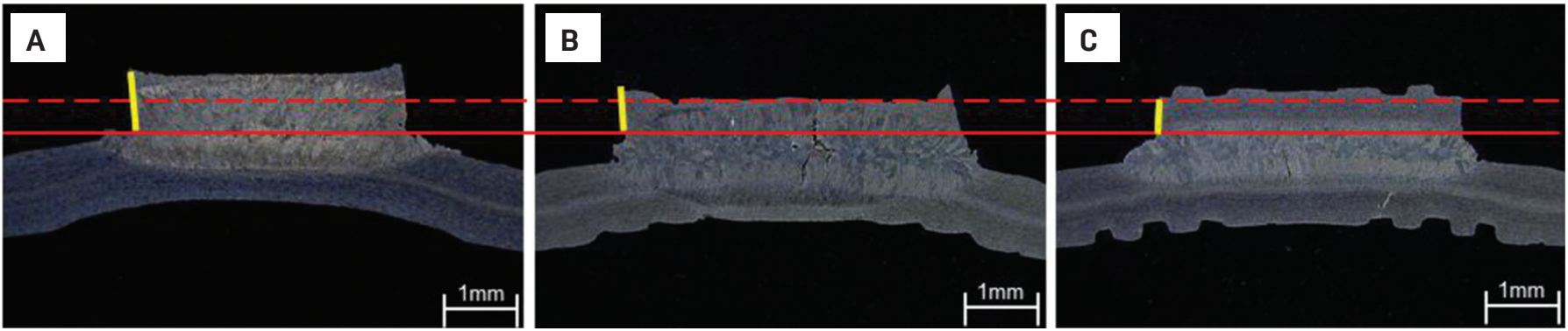

Fig. 17 - Crack length within fractured cross-tension specimens as a function of electrode face design: A - Textured; B - MRD Ring HI; C - MRD Ring H2.
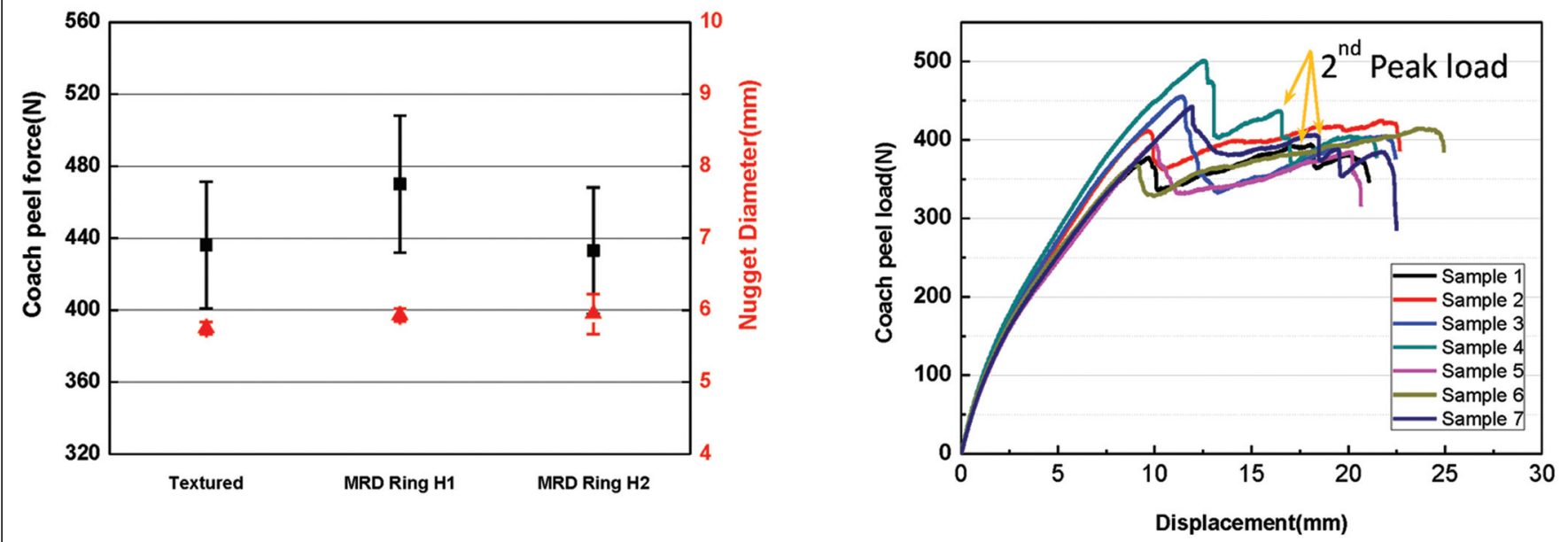

Fig. $18-A-$ Coach-peel strength and weld nugget diameter as a function of electrode face design (textured, MRD Ring $\mathrm{HI}$, and MRD Ring H2); B - load displacement curves for MRD Ring H2 welds.

ture, which reduced the tensile shear energy absorption at peak load compared to the MRD electrode designs. MRD Ring H2 had the greatest penetration of the rings with their associated cooling effect, and consequently exhibited the smallest nugget angles at the faying interface, leading to reduced cross-tension strength. Of the designs investigated, the MRD design, Ring H1, provided the best performance because of its ability to create larger nugget diameters and robust microstructures for a given electrode size and weld schedule.

'Eyelash'-like microstructures were found for welds produced by textured and MRD Ring $\mathrm{H} 1$ electrodes and were attributed to subsolidus grain boundary liquation. Neither the 'eyelash' microstructure in the HAZ nor cracks within the weld nugget influenced crack path.

Subsequent work will investigate fatigue performance of welds with varying electrode designs, and optimization of the MRD electrode face topography will be considered.

\section{Acknowledgments}

The authors would like to acknowledge the financial support of GM Research and Development Center, the National Natural Science Foundation of China (Grant Nos. U1564204, 51322504), and the National Key Research and Development Program of China (Grant No. 2016YFB010160608).

\section{References}

1. Sigler, D. R., Carlson, B. E., and Janiak, P. 2013. Improving aluminum resist- ance spot welding in automotive structures. Welding Journal 92(6): 64-s to 72-s.

2. Li, Y., Yan, F., and Luo, Z. 2015. Weld growth mechanisms and failure behavior of three-sheet resistance spot welds made of 5052 aluminum alloy. Journal of Materials Engineering and Performance 24(6): 2546-2555.

3. Cadillac CT6 Insurer Overview. 2016. genuinegmparts.com/pdf/cadillac-aluminumrepair-network-ct6-insurance-overview.pdf.

4. Maddela, S., and Carlson, B. E. Corrosion characterization of resistance spot welded aluminum and steel couple. Submitted to Corrosion Science.

5. Florea, R. S, and Bammann, D. J. 2013. Welding parameters influence on $\mathrm{fa}$ tigue life and microstructure in resistance spot welding of 6061-T6 aluminum alloy. Materials and Design 45: 456-465.

6. Shen, Q., and Li, Y.-B. 2011. Impact of external magnetic field on weld quality of resistance spot welding. Journal of Manufacturing Science and Engineering 133(5): 051001-1

7. Florea, R. S., and Solanki, K. N. 2012. 

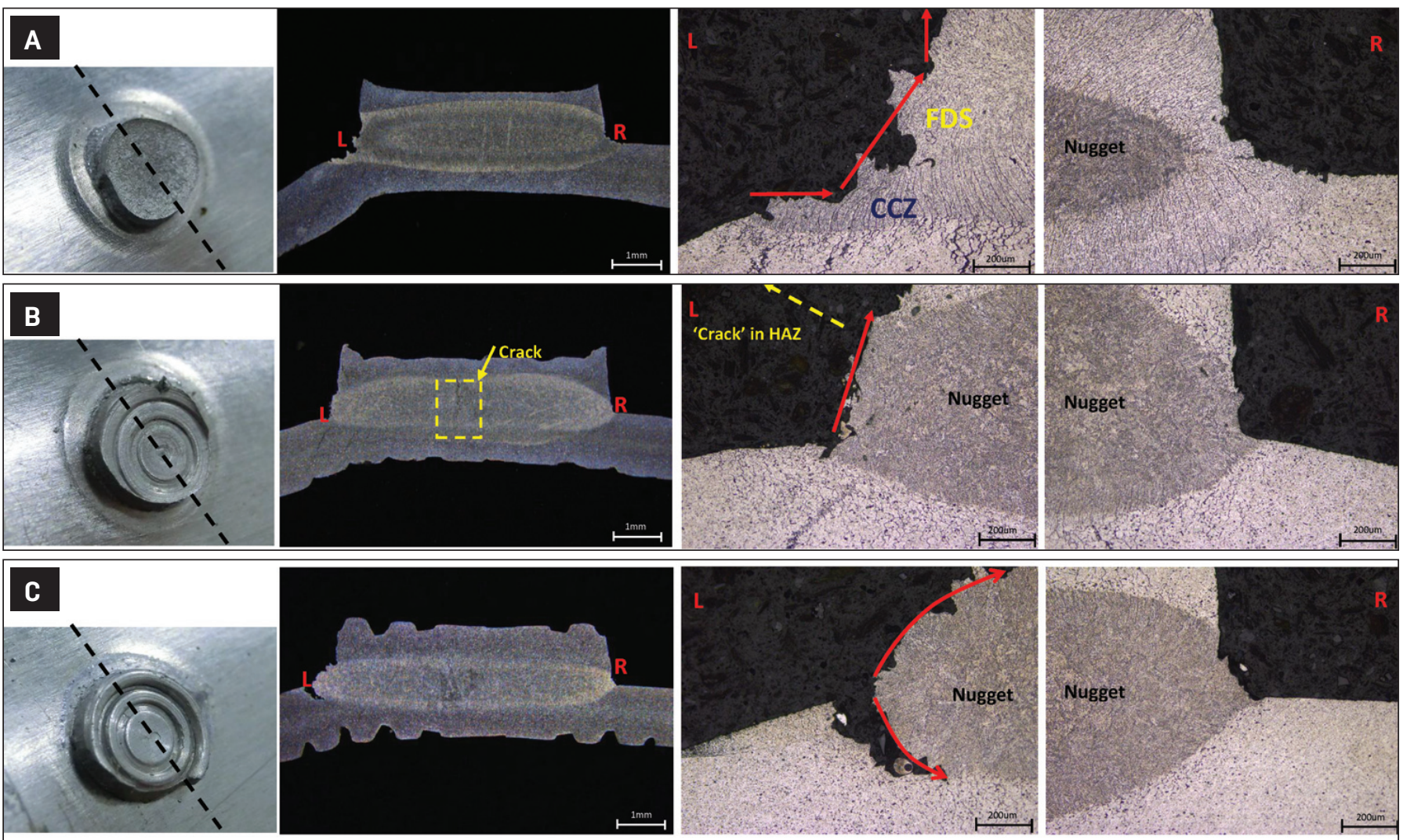

Fig. 19 - Crack path within fractured coach-peel specimens as a function of electrode face design: A - Textured; B - MRD Ring $\mathrm{HI}$; C - MRD Ring H2.

Resistance spot welding of 6061-T6 aluminum: Failure loads and deformation. Material and Design 34: 624-630.

8. Chang, B. H., Du, D., Sui, B., Zhou, Y., Wang, Z., and Heidarzadeh, F. 2007. Effect of forging force on fatigue behavior of spot welded joints of aluminum alloy 5182. J. Manuf. Sci. Eng. 129(1): 95-100.

9. Wei, P. S., and Wu, T. H. 2014. Effects of electrode contact condition on electrical dynamic resistance during resistance spot welding. Sci. Technol. Weld. Join. 19(2): 173180.

10. Al Naimi, I. K., and Al Saadi, M. H. 2015. Influence of surface pretreatment in resistance spot welding of aluminum AA105. Production \& Manufacturing Research 3(1): 185-200.

11. Arrington Jr., S. E. 1995. Twisting electrodes improve tip life and weld quality on resistance spot welded aluminum sheet. Aluminum Applications for Automotive Design. SAE Paper 950717.

12. Fronius International. 2014. fronius.com/cps/rde/xchg/SID-3AC27A9BF495FC44/fronius_international/hs.xsl/79_3 3390_ENG_HTML.htm\#.VBme ZaPU-70.

13. Crinon, E., and Evans, J. T. 1998. The effect of surface roughness, oxide film thickness and interfacial sliding on the electrical contact resistance of aluminum. Mater. Sci. Eng. A 242(1-2): 121-128.
14. Luo, Z., and Ao, S. 2015. Application of pre-heating to improve the consistency and quality in AA5052 resistance spot welding. Journal of Materials Engineering and Performance 24(10): 3881-3891.

15. Sigler, D. R., and Schroth, J. G. 2010. New electrode face geometries for spot welding aluminum. AWS Sheet Metal Welding Conference XIV, Livonia, Mich.: 11-14.

16. Sigler, D. R., Carlson, B. E., and Janiak, P. Oct. 22-24, 2014. A preliminary assessment of GM's Multi-Ring Domed (MRD) electrode for alternately welding aluminumto-aluminum and steel-to-steel stack-ups. AWS Sheet Metal Welding Conference XVI, Livonia, Mich.

17. Sigler, D. R., and Carlson, B. E. Oct.
2-5, 2012. Aluminum resistance spot welding electrode degradation. AWS Sheet Metal Welding Conference XV, Livonia, Mich.

18. ISO 4287:1997, Geometrical Product Specifications (GPS) - Surface texture: Profile method - Terms, definitions and surface texture parameters. International Organization for Standardization, Geneva.

19. Sigler, D. R., and Karagoulis, M. J. Dec. 2, 2011. Weld schedule for resistance spot welding of aluminum alloy workpieces. U.S. Patent Application 2013/ 0048613.

20. Kou, S. 2003. Welding Metallurgy, $2^{\text {nd }}$ ed. Wiley, Hoboken.

21. Elmer, J. W., Allen, S. M., and Eagar, T. W. 1989. Microstructural development

Table A - Nugget Diameter and Thickness Referred in Fig. 5

\begin{tabular}{|c|c|c|c|c|c|c|}
\hline \multirow{2}{*}{$\begin{array}{c}\text { Sample } \\
\text { No. }\end{array}$} & \multicolumn{3}{|c|}{ Diameter (Unit: mm) } & \multicolumn{3}{|c|}{ Thickness (Unit: mm) } \\
\hline & Textured & $\begin{array}{c}\text { MRD } \\
\text { Ring HI }\end{array}$ & $\begin{array}{c}\text { MRD } \\
\text { Ring H2 }\end{array}$ & Textured & $\begin{array}{c}\text { MRD } \\
\text { Ring H1 }\end{array}$ & $\begin{array}{c}\text { MRD } \\
\text { Ring H2 }\end{array}$ \\
\hline Sample 1 & 5.68 & 6.03 & 6.34 & 1.39 & 1.46 & 1.08 \\
\hline Sample 2 & 5.70 & 5.95 & 5.72 & 1.69 & 1.39 & 0.89 \\
\hline Sample 3 & 5.86 & 5.81 & 5.78 & 1.49 & 1.28 & 1.01 \\
\hline Ave. & 5.75 & 5.93 & 5.95 & 1.52 & 1.38 & 1.00 \\
\hline Std. & 0.08 & 0.09 & 0.28 & 0.12 & 0.07 & 0.08 \\
\hline
\end{tabular}


during solidification of stainless steel alloys. Metall. Trans. A 20(10): 2117-2131.

22. DebRoy, T., and David, S. A. 1995. Physical processes in fusion welding. Rev. Mod. Phys. 67: 85-112.

23. Wei, P. S. 2012. The physics of weld bead defects. Welding Processes. Ed. R. Kovacevic. InTech Co., Rijeka, Croatia: pp. 395414.

24. Miyazaki, M., and Nishio, K. 1990. Quantitative investigation of heat-affected zone cracking in aluminum alloy A6061. Welding Journal 69(9): 362-s to 372-s.

25. Malin, V. 1995. Study of metallurgical phenomena in the HAZ of 6061-T6 aluminum welded joints. Welding Journal 74(9): 305-s to 318-s.

26. Senkara, J., and Zhang, H. 2000. Cracking in spot welding aluminum alloy AA5754. Welding Journal 79(7): 194-201.

27. Zhang, H., Senkara, J., and Wu, X. 2002. Suppressing cracking in resistance welding AA5754 by mechanical means. Journal of Manufacturing Science and Engineering: 79-85.

28. Heidarzadeh, F. 2004. Mechanical and fatigue properties of resistance spotwelded AA5182 sheets. Master's thesis, University of Toronto, Ontario, Canada.

\section{Appendix}

Raw data including nugget diameter, thickness, weld thinning, distortion, and total energy, as well as lap-shear, coach-peel peak force, and cross-tension peak force for the welds in the experiments are displayed. The Ave. and Std. represent the mean value and standard deviation of all tested samples, respectively.
LIN DENG and YONGBING LI (yongbinglee@sjtu.edu.cn) are with the Shanghai Key Laboratory of Digital Autobody Engineering, Shanghai Jiao Tong University, Shanghai, China. LI is also with the State Key Laboratory of Mechanical System and Vibration, Shanghai Jiao Tong University, Shanghai, China. BLAIR E. CARLSON and DAVID R. SIGLER are with the Manufacturing Systems Research Lab, General Motors Research and Development Center, Warren, Mich
Table B - Weld Thinning and Distortion Referred in Fig. 6

\begin{tabular}{ccccccc}
$\begin{array}{c}\text { Sample } \\
\text { No. }\end{array}$ & \multicolumn{3}{c}{ Thinning (Unit: mm) } & \multicolumn{3}{c}{ Distortion (Unit: mm) } \\
\cline { 2 - 7 } & Textured & $\begin{array}{c}\text { MRD } \\
\text { Ring H1 }\end{array}$ & $\begin{array}{c}\text { MRD } \\
\text { Ring H2 }\end{array}$ & Textured & $\begin{array}{c}\text { MRD } \\
\text { Ring H1 }\end{array}$ & $\begin{array}{c}\text { MRD } \\
\text { Ring H2 }\end{array}$ \\
\hline Sample 1 & 0.35 & 0.26 & 0.09 & 0.27 & 0.22 & 0.07 \\
Sample 2 & 0.35 & 0.22 & 0.15 & 0.27 & 0.23 & 0.07 \\
Sample 3 & 0.35 & 0.22 & 0.22 & 0.32 & 0.2 & 0.1 \\
Ave. & 0.35 & 0.23 & 0.15 & 0.29 & 0.22 & 0.08 \\
Std. & 0.00 & 0.02 & 0.05 & 0.02 & 0.01 & 0.02 \\
\hline
\end{tabular}

Table C - Tensile-Shear Peak Force and Total Energy Referred in Fig. 13

\begin{tabular}{ccccccc}
$\begin{array}{c}\text { Sample } \\
\text { No. }\end{array}$ & \multicolumn{3}{c}{ Peak Force (Unit: N) } & \multicolumn{3}{c}{ Total Energy (Unit: J) } \\
\cline { 2 - 7 } & Textured & $\begin{array}{c}\text { MRD } \\
\text { Ring H1 }\end{array}$ & $\begin{array}{c}\text { MRD } \\
\text { Ring H2 }\end{array}$ & Textured & $\begin{array}{c}\text { MRD } \\
\text { Ring H1 }\end{array}$ & $\begin{array}{c}\text { MRD } \\
\text { Ring H2 }\end{array}$ \\
\hline Sample 1 & 3156 & 3143 & 2896 & 1.31 & 1.51 & 1.12 \\
Sample 2 & 3106 & 3089 & 2945 & 1.25 & 1.34 & 1.62 \\
Sample 3 & 3099 & 3420 & 3104 & 1.16 & 1.74 & 1.54 \\
Sample 4 & 3149 & 2941 & 3319 & 1.25 & 1.40 & 1.67 \\
Sample 5 & 3129 & 3129 & 3258 & 1.14 & 1.67 & 1.66 \\
Sample 6 & 3000 & 3049 & 2824 & 1.02 & 1.43 & 1.20 \\
Sample 7 & 3092 & 3248 & 3225 & 1.11 & 1.46 & 1.42 \\
Ave. & 3104 & 3146 & 3081 & 1.17 & 1.51 & 1.46 \\
Std. & 48 & 142 & 180 & 0.09 & 0.14 & 0.21 \\
\hline
\end{tabular}

Table D - Cross-Tension Peak Force Referred in Fig. 15

\begin{tabular}{cccc} 
Sample & \multicolumn{3}{c}{ Cross-Tension Peak Force (Unit: N) } \\
\cline { 2 - 4 } No. & Textured & MRD Ring H1 & MRD Ring H2 \\
\hline Sample 1 & 2026 & 2016 & 1581 \\
Sample 2 & 2234 & 1931 & 1652 \\
Sample 3 & 2359 & 2127 & 1589 \\
Sample 4 & 2039 & 1860 & 1692 \\
Sample 5 & 1867 & 1881 & 1491 \\
Sample 6 & 2020 & 1960 & 1652 \\
Sample 7 & 2012 & 2175 & 1483 \\
Ave. & 2080 & 1993 & 1592 \\
Std. & 151 & 111 & 75 \\
\hline
\end{tabular}

Table E - Coach-Peel Peak Force Referred in Fig. 18

\begin{tabular}{cccc} 
Sample & \multicolumn{3}{c}{ Coach-Peel Peak Force (Unit: N) } \\
\cline { 2 - 4 } No. & Textured & MRD Ring H1 & MRD Ring H2 \\
\hline Sample 1 & 513 & 420 & 394 \\
Sample 2 & 426 & 473 & 425 \\
Sample 3 & 432 & 473 & 455 \\
Sample 4 & 393 & 442 & 501 \\
Sample 5 & 434 & 451 & 394 \\
Sample 6 & 448 & 479 & 415 \\
Sample 7 & 409 & 550 & 443 \\
Ave. & 436 & 470 & 433 \\
Std. & 35 & 36 & 35 \\
\hline
\end{tabular}

